\title{
Liraglutide 3.0 mg for Weight Management: A Population Pharmacokinetic Analysis
}

\author{
Rune V. Overgaard ${ }^{1} \cdot$ Kristin C. Petri $^{1} \cdot$ Lisbeth V. Jacobsen $^{1} \cdot$ Christine B. Jensen $^{1}$
}

Published online: 19 May 2016

(C) The Author(s) 2016. This article is published with open access at Springerlink.com

\begin{abstract}
Background and Objectives This analysis used a population pharmacokinetic approach to identify covariates that influence plasma exposure of liraglutide $3.0 \mathrm{mg}$, a glucagon-like peptide-1 (GLP-1) receptor agonist approved for weight management in overweight and obese individuals. Methods Samples for pharmacokinetic analysis were drawn at weeks 2, 12 and 28 of the phase IIIa SCALE Obesity and Prediabetes $(N=2339)$ and SCALE Diabetes $(N=584)$ trials. Dose proportionality of liraglutide in obese subjects was investigated using data from a phase II dose-finding study $(N=331)$.

Results Dose-proportional exposure of liraglutide up to and including $3.0 \mathrm{mg}$ was confirmed. Body weight and sex influenced exposure of liraglutide $3.0 \mathrm{mg}$, while age $\geq 70$ years, race, ethnicity and baseline glycaemic status did not. Compared with a reference subject weighing $100 \mathrm{~kg}$, exposure of liraglutide $3.0 \mathrm{mg}$ was $44 \%$ lower for a subject weighing $234 \mathrm{~kg}$ (90\% CI 41-47), $41 \%$ higher for a subject weighing $60 \mathrm{~kg}$ ( $90 \%$ CI 37-46), and $32 \%$ higher (90\% CI 28-35) in females than males with the same body weight. Neither injection site nor renal function significantly influenced exposure of liraglutide $3.0 \mathrm{mg}$ (post hoc analysis).

Conclusion Population pharmacokinetics of liraglutide up to and including $3.0 \mathrm{mg}$ daily in overweight and obese adults demonstrated dose-proportional exposure, and
\end{abstract}

Electronic supplementary material The online version of this article (doi:10.1007/s40262-016-0410-7) contains supplementary material, which is available to authorized users.

Rune V. Overgaard

RUVO@novonordisk.com

1 Novo Nordisk A/S, Vandtårnsvej 108, 2860 Søborg, Denmark limited effect of covariates other than sex and body weight. These findings were similar to those previously observed with liraglutide up to $1.8 \mathrm{mg}$ in subjects with type 2 diabetes mellitus. Further analysis of exposure-response relationship and its effect on dose requirements is addressed in a separate publication.

\section{Key Points}

In this analysis of obese/overweight subjects with and without type 2 diabetes mellitus, doseproportional exposure of liraglutide $(\leq 3.0 \mathrm{mg})$ was confirmed.

Body weight and sex influenced exposure of liraglutide $3.0 \mathrm{mg}$, while age $\geq 70$ years, race, ethnicity and glycaemic status did not.

Moreover, neither injection site nor renal function influenced exposure of liraglutide $3.0 \mathrm{mg}$.

\section{Background}

Liraglutide is an acylated human glucagon-like peptide-1 (GLP-1) receptor agonist with $97 \%$ amino acid sequence homology to human GLP-1 (7-37). Liraglutide $1.8 \mathrm{mg}$ daily (Victoza ${ }^{\circledR}$; Novo Nordisk A/S, Bagsvaerd, Denmark) is widely approved for the treatment of type 2 diabetes mellitus (T2DM), and liraglutide $3.0 \mathrm{mg}$ is approved in the US [1], Canada [2], Europe [3] and Mexico [4] for weight management.

In randomised clinical trials, liraglutide $3.0 \mathrm{mg}$ led to significant weight loss, weight loss-dependent 
improvement in weight-related comorbidity, and improved glycaemic control $[5,6]$. The mechanism for liraglutidemediated weight loss has been shown to involve an increase in hypothalamic satiety signals coupled with a decrease in appetite-stimulating signals, resulting in reduced energy intake $[7,8]$.

Obesity, defined as a body mass index (BMI) $\geq 30 \mathrm{~kg} \mathrm{~m}^{-2}$ [9], is associated with multiple progressive comorbidities such as T2DM [10, 11], hypertension, high cholesterol, stroke, heart disease, several cancer types [12, 13] and a 5- to 10-year reduction in life expectancy [14]. Obese individuals are at greater risk for numerous physical symptoms [15-19] and psychosocial difficulties [20], and have poorer health-related quality of life than normalweight individuals [21]. The individual and societal impact of obesity makes interventions to reduce its prevalence a public health priority [22].

Behavioral intervention using diet and exercise is typically the initial approach for weight management, but when this is not sufficient to produce meaningful weight loss, pharmacotherapy may be a valuable adjunct [23-25]. The Satiety and Clinical Adiposity-Liraglutide Evidence in non-diabetic and diabetic people (SCALE) phase IIIa clinical trial programme investigated the efficacy and safety of liraglutide $3.0 \mathrm{mg}$ (once-daily subcutaneous injection) as adjunct to a reduced-calorie diet and increased physical activity. After 56 weeks, mean body weight losses of $8.0 \%$ (vs. $2.6 \%$ with placebo) and $5.9 \%$ (vs. $2.2 \%$ with placebo) were observed in the SCALE Obesity and Prediabetes [5] and SCALE Diabetes [6] trials, respectively.

The efficacy of liraglutide $3.0 \mathrm{mg}$ was consistent across various demographic subgroups. However, there was a tendency for less weight loss in subjects with a BMI $>40 \mathrm{~kg} \mathrm{~m}^{-2}$ and greater weight loss in females versus males. Previously, a population pharmacokinetic analysis in patients with T2DM [26] demonstrated that body weight and sex were relevant factors for the exposure level of liraglutide (at doses up to $1.8 \mathrm{mg}$ ), suggesting that differences in clinical response to liraglutide may be associated with differences in exposure.

This analysis demonstrated that, in overweight and obese adults, population pharmacokinetics of liraglutide up to and including $3.0 \mathrm{mg}$ daily was similar to that observed with liraglutide up to $1.8 \mathrm{mg}$ in subjects with T2DM, with dose-proportional exposure and limited effect of covariates other than sex and body weight. Characterisation of individual exposure levels and key determinants of exposure allows for subsequent investigation of the exposure-response relationship, thereby informing dosing recommendations for liraglutide $3.0 \mathrm{mg}$ in weight management.

\section{Methods}

\subsection{Materials}

\subsubsection{Data Sources for Population Pharmacokinetic Analysis of Liraglutide $3.0 \mathrm{mg}$}

SCALE Obesity and Prediabetes (Trial 1) was a randomised, double-blind, placebo-controlled, multicentre, phase IIIa trial examining the efficacy and safety of liraglutide $3.0 \mathrm{mg}$ versus placebo, as adjunct to diet and exercise, in obese (BMI $\geq 30 \mathrm{~kg} \mathrm{~m}^{-2}$ ) or overweight (BMI $\geq 27-29.9 \mathrm{~kg} \mathrm{~m}^{-2}$ ) adults with at least one weight-related comorbidity (treated or untreated hypertension and/or dyslipidaemia) over 56 weeks. In this trial, 3731 subjects were randomised $2: 1$ to liraglutide $3.0 \mathrm{mg}(N=2487)$ or placebo $(N=1244)$ injections once daily, starting at $0.6 \mathrm{mg} /$ day, with weekly dose increments of $0.6 \mathrm{mg}$ up to a maximum of $3.0 \mathrm{mg}$ daily (Trial 1 [5]). A total of 2339 subjects from the SCALE Obesity and Prediabetes trial were included in this population pharmacokinetic analysis.

A single blood sample for plasma liraglutide concentration measurement was drawn from all subjects included in the pharmacokinetic analysis from Trial 1, at weeks 2 (dose escalation period), 12 and 28 after randomisation. The date, time, liraglutide dose and injection site for the three injections prior to each blood sampling were recorded. In addition, week 16 data values were included from a substudy $\left(N=52 ; 50\right.$ maximum concentration $\left[C_{\max }\right]$ values available) in which subjects who administered liraglutide in the evening had blood drawn for liraglutide bioanalysis at approximately 10, 11, 12 and $14 \mathrm{~h}$ after dosing, to obtain exposure values around $C_{\max }$ for liraglutide $3.0 \mathrm{mg}$.

SCALE Diabetes (Trial 2) was a randomised, doubleblind, placebo-controlled, parallel group, multicentre, phase IIIa trial examining the efficacy and safety of liraglutide $3.0 \mathrm{mg}$ and $1.8 \mathrm{mg}$ versus placebo in overweight or obese (BMI $\geq 27 \mathrm{~kg} \mathrm{~m}^{-2}$ ) adults with T2DM (glycated haemoglobin $\left[\mathrm{HbA}_{1 \mathrm{c}}\right]$ 53-86 $\mathrm{mmol} \mathrm{mol}^{-1}$ [7.0-10.0\%]), treated with diet and exercise alone or combined with one to three oral hypoglycaemic agents (OHAs), including metformin, a thiazolidinedione and/or a sulphonylurea. Subjects in Trial $2(N=846)$ were randomised $2: 1: 1$ to liraglutide $3.0 \mathrm{mg}(N=423)$, liraglutide $1.8 \mathrm{mg}(N=211)$ or placebo $(N=212)$ injections once daily, starting at $0.6 \mathrm{mg} / \mathrm{day}$, with weekly $0.6 \mathrm{mg}$ dose increments up to a maximum of $3.0 \mathrm{mg} /$ day (Trial 2 [6]).

Blood sampling was performed at weeks 2, 12 and 28 for all subjects included in the pharmacokinetic analysis from Trial 2, as described for subjects from Trial 1. The date, time, dose and injection site of liraglutide for the 
three injections occurring prior to each blood sampling were recorded.

Only records with a complete (all three doses) and unambiguous (constant dose level; only one daily dose) dosing history for the 3 days leading up to each visit were included; inadequate dosing history resulted in exclusion of 1185 of 8859 records from the main pharmacokinetic analysis. The available concentration data were used to estimate individual area under the curve (AUC) values, using the final population pharmacokinetic model (with the same population level parameter values as in the original analysis).

\subsubsection{Data Source for Analysis of Dose Proportionality of Liraglutide at Doses Up to $3.0 \mathrm{mg}$}

Data from 331 adults enrolled in a phase II dose-finding trial with liraglutide and an open-label orlistat comparator arm (Trial 3 [27]) were used in a dose-proportionality assessment. In this 20-week, randomised, double-blind, placebo-controlled, six-armed, parallel group, multicentre trial, the response to a range of liraglutide doses was examined in obese individuals (BMI $\geq 30$ and $\leq 40 \mathrm{~kg} \mathrm{~m}^{-2}$ ) without T2DM. Subjects included in the dose-proportionality analysis were randomised $1: 1: 1: 1: 1: 1$ to receive liraglutide $1.2 \mathrm{mg}(N=88), 1.8 \mathrm{mg}(N=80)$, $2.4 \mathrm{mg}(N=77), 3.0 \mathrm{mg}(N=86)$ or placebo $(N=98)$ once daily (initiated at $0.6 \mathrm{mg} / \mathrm{day}$, with weekly $0.6 \mathrm{mg}$ increments up to the required dose) or orlistat $(120 \mathrm{mg}$ thrice daily).

Blood sampling for dose proportionality assessment was performed at week 20 during an oral glucose tolerance test visit, in the morning, 10-14 $\mathrm{h}$ after dose administration the previous evening. Samples were drawn at 0, 60 and $120 \mathrm{~min}$ following glucose ingestion. The time of blood sampling relative to the previous liraglutide dose was not recorded.

\subsection{Population Pharmacokinetic Model}

A prespecified approach [28] was used for the population pharmacokinetic analysis, which included estimation of a base model without covariates and a full model with all covariates included. Only the full covariate model is described here.

The population pharmacokinetic model was developed and validated according to the US FDA and European Medicines Agency (EMA) guidelines for pharmacokinetic modelling [29, 30]. Full details of the model qualification are included in the Online Resource, Sect. 1. This was a one-compartment model with first-order absorption and elimination. It was parameterised by absorption rate $(\mathrm{Ka})$, apparent clearance $(\mathrm{CL} / F)$ and apparent volume $(\mathrm{V} / F)$, where covariate effects were implemented for clearance only, as:

$$
\begin{aligned}
\mathrm{CL} / F_{i}= & \mathrm{TVCL} \cdot E_{\mathrm{weight}} \cdot E_{\mathrm{dose}} \cdot E_{\mathrm{sex}} \cdot E_{\mathrm{age}} \cdot E_{\text {ethnicity }} \\
& \cdot E_{\text {disease status }} \cdot \operatorname{Exp}\left(\eta_{i}\right)
\end{aligned}
$$

where TVCL is the typical liraglutide apparent clearance for a reference subject profile (female; $<70$ years of age; $100 \mathrm{~kg}$ body weight [rounded value close to mean body weight]; White, non-Hispanic or -Latino, and without diabetes or prediabetes, taking liraglutide $3.0 \mathrm{mg}$ once daily), and $\eta$ describes the random interindividual variability, assumed to be normally distributed. To ensure identifiability of the model with the sparsely sampled data, the liraglutide absorption rate constant was set to a value $\left(0.0806 \mathrm{~L} / \mathrm{h}^{-1}\right)$ estimated from a population pharmacokinetic model based on a multiple-dose clinical pharmacology study in obese subjects ([8]; data on file), and the assumption that this parameter can be fixed without affecting the conclusions was verified by sensitivity analyses. A proportional error model was used to describe the residual variability of liraglutide concentrations. Parameter estimates for the full covariate model are described in the Online Resource (Table S1).

The full covariate model was used to obtain parameter estimates and confidence intervals (CI) for the following covariates: age ( $<$ or $\geq 70$ years), baseline body weight (minimum $60 \mathrm{~kg}$; maximum $234 \mathrm{~kg}$, relative to a $100 \mathrm{~kg}$ person), sex, race (White, Black or African American, Asian, Other [including American Indian or Alaskan native, native Hawaiian or other Pacific Islander]), ethnicity (Hispanic or Latino, non-Hispanic or -Latino), baseline glycaemic status (non-diabetic, prediabetic or with T2DM), and liraglutide dose (1.8 or $3.0 \mathrm{mg}$ ).

Likelihood profiling was used to determine geometric means and $90 \%$ CI for each investigated covariate. Differences in pharmacokinetic parameters were considered relevant if the $90 \% \mathrm{CI}$ of the effect fell outside the standard bioequivalence limits (0.80-1.25).

Graphical data quality analyses, including goodness-offit plots, were conducted prior to performing the population pharmacokinetic analysis, as described in the Online Resource (Sect. 2; Figs. S1, S2).

\subsection{Exposure Assessment for Dose Proportionality}

The exposure data from Trial 3 were obtained by estimating the full population pharmacokinetic model (developed using data from Trials 1 and 2) on data from Trial 3, with all parameters fixed. This provided individual post hoc empirical Bayes estimates of the exposure level for subjects in Trial 3, which were used to evaluate dose proportionality. 


\subsection{Post Hoc Analysis}

A post hoc analysis of the effect of (1) injection site and (2) renal function on $\mathrm{CL} / F$ of liraglutide was performed, using data from Trial 1 (injection site; renal function on CL/F of liraglutide) and Trial 2 (renal function on $\mathrm{CL} / F$ of liraglutide), by comparing individual values of covariateadjusted $\mathrm{CL} / F$. For injection-site analysis, values were obtained from subjects injecting into the abdomen, thigh or upper arm. Baseline renal function was determined by estimating creatinine clearance $(\mathrm{CrCl})$ using the Chronic Kidney Disease-Epidemiology Collaboration (CKD-EPI) equation [31]. The effects of renal function and injection site were not part of the prespecified analysis; this post hoc analysis is therefore presented as the primary result for the influence of these parameters on CL/F of liraglutide.

\subsection{Liraglutide Assay}

Total liraglutide plasma concentration was determined using a validated enzyme-linked immunosorbent assay (ELISA) [32]. The lower limit of quantification (LLOQ) was $30 \mathrm{pmol} \mathrm{L}^{-1}$ for the ELISAs used in Trials 1 and 2, and $18 \mathrm{pmol} \mathrm{L}^{-1}$ for the ELISA used in the dose-finding trial (Trial 3). For Trials 1 and 2, the intra- and interassay precision was $<12.9$ and $9.4 \%$, respectively (data on file). For Trial 3, the intra- and interassay precision was $<6.5$ and $10.1 \%$, respectively [33].

\subsection{Ethical Statements}

The study protocols for all trials in this analysis were approved by local Institutional Review Boards and Ethics Committees. All trials were conducted in accordance with the Declaration of Helsinki [34] and Good Clinical Practice guidelines [35], and all patients provided written informed consent before participation.

\subsection{Data Analysis Software}

SPLUS, version 8.2 (TIBCO, Palo Alto, CA, USA) was used for data-file processing, exploratory-data analysis and plotting. NONMEM, version 7.1.2 (ICON Development Solutions, Ellicott City, MD, USA) was used for the population pharmacokinetic analysis and simulation.

\section{Results}

This population pharmacokinetic analysis used data from two phase IIIa trials to examine the effects of various covariates on plasma exposure of liraglutide $3.0 \mathrm{mg}$ in overweight and obese individuals. Dose proportionality of liraglutide at doses up to $3.0 \mathrm{mg}$ in obese subjects was also investigated using data from one phase II trial. In this study, we present the results of each analysis.

\subsection{Demographics}

Tables 1 and S2 (Online Resource) show baseline demographics in all three trial populations. Subjects in the population pharmacokinetic analysis (Table 1) had a mean age of 47 years, and $2.5 \%(n=73)$ were aged $\geq 70$ years. Most subjects were female (72\%), White (85\%), and nonHispanic or -Latino $(90 \%)$. Mean body weight and BMI were $106 \pm 21 \mathrm{~kg}$ and $38 \pm 7 \mathrm{~kg} \mathrm{~m}^{-2}$, respectively. In all, $20 \%$ of subjects had T2DM (all in Trial 2), and the majority had normal renal function or mild renal impairment. In comparison, sex and age distribution in the dosefinding trial population was similar to that in the pharmacokinetic analysis population, although in the former trial almost all subjects were White (99\%), and mean body weight $(98 \pm 13 \mathrm{~kg})$ and $\mathrm{BMI}\left(35 \pm 3 \mathrm{~kg} \mathrm{~m}^{-2}\right)$ were somewhat lower.

\subsubsection{Structural Model}

Parameter estimates and qualifications of the pharmacokinetic model are available in the Online Resource, Sect. S1. The pharmacokinetics of liraglutide were adequately described by a one-compartment model with first-order absorption and first-order elimination, with $\mathrm{CL} / F$ ranging from 0.9 to $1.4 \mathrm{~L} / \mathrm{h}$. The apparent clearance was 0.9 and 1.0 $\mathrm{L} / \mathrm{h}$ for a non-diabetic or diabetic female, respectively, and 1.1-1.4 L/h for a non-diabetic or diabetic male, with other covariate factors resembling those of the reference subject (100 kg body weight, White, non-Hispanic or -Latino, $<70$ years of age, taking liraglutide $3.0 \mathrm{mg}$ once daily).

\subsection{Dose Proportionality of Liraglutide at Doses Up to $3.0 \mathrm{mg}$}

Model-derived AUCs by dose in this population supported dose proportionality of liraglutide up to and including $3.0 \mathrm{mg}$ (Fig. 1). Demographics of subjects from the phase II dose-finding trial included in the dose-proportionality analysis are included in the Online Resource, Table S2.

\subsection{Population Pharmacokinetic Analysis}

\subsubsection{Subject Baseline Characteristics}

Table 1 describes the baseline demographics of subjects included in the population pharmacokinetic analysis. Mean body weight and BMI for all subjects were $106 \mathrm{~kg}$ and $38 \mathrm{~kg} \mathrm{~m}^{-2}$, respectively. As expected, despite similar 
Table 1 Summary of baseline characteristics for subjects included in the pharmacokinetic evaluation

\begin{tabular}{|c|c|c|c|}
\hline Covariate & $\begin{array}{l}\text { Trial } 1 \\
{[N=2339]}\end{array}$ & $\begin{array}{l}\text { Trial } 2 \\
{[N=584]}\end{array}$ & $\begin{array}{l}\text { Total } \\
{[N=2923]}\end{array}$ \\
\hline \multicolumn{4}{|c|}{ Liraglutide dose, mg $[n(\%)]$} \\
\hline 1.8 & $0(0)$ & $191(32.5)$ & $191(6.5)$ \\
\hline 3.0 & $2339(100)$ & $393(67.5)$ & $2732(93.5)$ \\
\hline \multicolumn{4}{|l|}{$\operatorname{Sex}[n(\%)]$} \\
\hline Female & $1831(78)$ & $281(48)$ & $2112(72)$ \\
\hline Male & $508(22)$ & $303(52)$ & $811(28)$ \\
\hline \multicolumn{4}{|l|}{ Age, years $[n(\%)]$} \\
\hline Mean (SD) & $45.2(12.0)$ & $54.7(10.5)$ & $47.1(12.3)$ \\
\hline$\geq 75$ & $4(0.2)$ & $9(1.5)$ & $13(0.4)$ \\
\hline $70-74$ & $32(1.4)$ & $28(4.8)$ & $60(2.1)$ \\
\hline $65-69$ & $91(3.9)$ & $67(11.5)$ & $158(5.4)$ \\
\hline $18-64$ & $2212(94.5)$ & $480(82.2)$ & $2692(92.1)$ \\
\hline \multicolumn{4}{|l|}{$\operatorname{Race}[n(\%)]^{\mathrm{a}}$} \\
\hline White & $1989(85)$ & $493(84.4)$ & $2482(84.9)$ \\
\hline Black/African American & $222(9.5)$ & $61(10.4)$ & $283(9.7)$ \\
\hline Asian & $82(3.5)$ & $14(2.4)$ & $96(3.3)$ \\
\hline Other & $46(2.0)$ & $16(2.8)$ & $62(2.1)$ \\
\hline \multicolumn{4}{|l|}{ Ethnic group $[n(\%)]$} \\
\hline Hispanic or Latino & $246(10.5)$ & $60(10.3)$ & $306(10.5)$ \\
\hline Non-Hispanic or -Latino & $2093(89.5)$ & $524(89.7)$ & $2617(89.5)$ \\
\hline \multicolumn{4}{|l|}{ Mean body weight, kg } \\
\hline \multicolumn{4}{|l|}{ Overall population } \\
\hline Mean (SD) & $106(21)$ & $106(22)$ & $106(21)$ \\
\hline Range & $65-234$ & 60-199 & $30-234$ \\
\hline \multicolumn{4}{|l|}{ Females } \\
\hline Mean (SD) & $102(19)$ & $100(19)$ & $102(19)$ \\
\hline Range & $65-218$ & $60-167$ & $60-218$ \\
\hline \multicolumn{4}{|l|}{ Males } \\
\hline Mean (SD) & $121(24)$ & $112(22)$ & $118(24)$ \\
\hline Range & $79-234$ & 75-199 & $75-234$ \\
\hline \multicolumn{4}{|l|}{ BMI, $\mathbf{k g ~ m}^{-2}$} \\
\hline \multicolumn{4}{|l|}{ Overall population } \\
\hline Mean (SD) & $38(6)$ & $37(7)$ & $38(7)$ \\
\hline Range & $27-77$ & $27-68$ & $27-77$ \\
\hline \multicolumn{4}{|l|}{ Females } \\
\hline Mean (SD) & $38(6)$ & $38(7)$ & $38(6)$ \\
\hline Range & $27-77$ & $27-68$ & $27-77$ \\
\hline \multicolumn{4}{|l|}{ Males } \\
\hline Mean (SD) & $38(7)$ & $36(7)$ & $38(7)$ \\
\hline Range & $27-70$ & $27-61$ & $27-70$ \\
\hline \multicolumn{4}{|l|}{ BMI categories $[n(\%)]$} \\
\hline$<29.9$ & $60(2.6)$ & $77(13.2)$ & $137(4.7)$ \\
\hline $30-34.9$ & $765(32.7)$ & $181(31.0)$ & $946(32.4)$ \\
\hline $35-39.9$ & $730(31.2)$ & $148(25.3)$ & $878(30.0)$ \\
\hline$\geq 40$ & $784(33.5)$ & $178(30.5)$ & $962(32.9)$ \\
\hline
\end{tabular}

Table 1 continued

\begin{tabular}{llll}
\hline Covariate & $\begin{array}{l}\text { Trial 1 } \\
{[N=2339]}\end{array}$ & $\begin{array}{l}\text { Trial 2 } \\
{[N=584]}\end{array}$ & $\begin{array}{l}\text { Total } \\
{[N=2923]}\end{array}$ \\
\hline Glycaemic status $[\boldsymbol{n}(\boldsymbol{\%})]$ & & & \\
Normoglycaemic & $897(38.3)$ & $0(0)$ & $897(30.7)$ \\
Prediabetic & $1442(61.7)$ & $0(0)$ & $1442(49.3)$ \\
Type 2 diabetes & $0(0)$ & $584(100)$ & $584(20.0)$ \\
Creatinine clearance, $\mathbf{~ m l / m i n ~ ( d e g r e e ~ o f ~ r e n a l ~ i m p a i r m e n t ) ~}$ \\
$\geq 90$ (normal) & $1194(51)$ & $295(51)$ & $1489(51)$ \\
$\geq 60$ and $<90$ (mild) & $1045(45)$ & $236(40)$ & $1281(44)$ \\
$\geq 30$ and $<60$ (moderate) & $99(4)$ & $52(9)$ & $151(5)$ \\
$<30$ (severe) & $1(0)$ & $1(0)$ & $2(0.0)$ \\
Injection site $[\boldsymbol{n}(\%)]^{\mathrm{b}}$ & & & \\
Abdomen & $1768(75.6)$ & NA \\
Thigh & $452(19.3)$ & \\
Upper arm & $113(4.8)$ & \\
Other & $6(0.3)$ & & \\
\hline
\end{tabular}

$B M I$ body mass index, $N A$ not applicable, $S D$ standard deviation

a The 'Other' race group for the covariate analysis included 'American Indian or Alaskan Native', 'Native Hawaiian or other Pacific Islander' and any 'Other'

${ }^{\mathrm{b}}$ Post hoc analysis, analysed in Trials 1 and 2

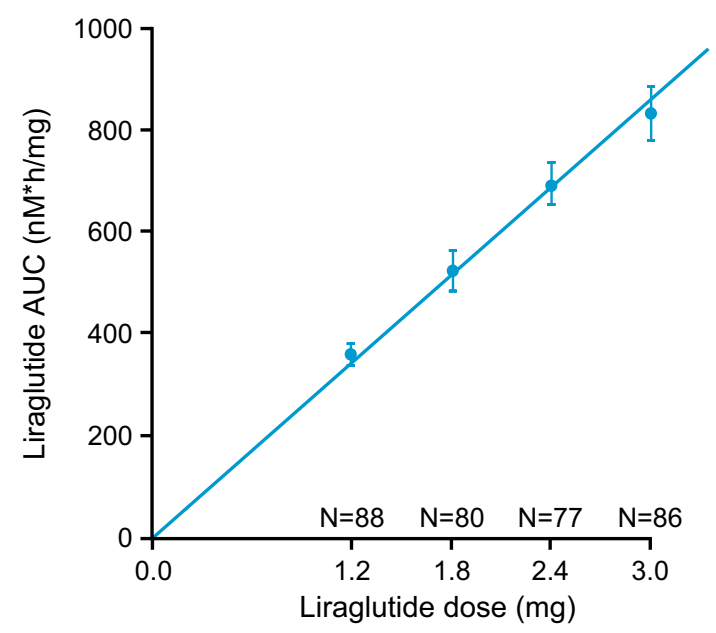

Fig. 1 Model-derived relationship between liraglutide AUC and dose in obese individuals. Data shown are from the phase II dose-finding trial (Trial 3; Astrup et al. [27]) and represent means and $95 \%$ CI. $A U C$ area under the curve, $C I$ confidence interval, $N$ number of subjects

baseline BMI in both sex groups, mean body weight was higher in men. Overall, the majority of subjects were White and non-Hispanic or -Latino. There was a higher proportion of females among subjects included in the pharmacokinetic analysis population from Trial 1. 


\subsubsection{Covariate Analysis}

The covariate analysis results were summarised for steadystate liraglutide exposure $\left(\mathrm{AUC}_{24}\right)$ relative to exposure for a reference subject (Table 1). The between-subject variability for liraglutide CL/F (hence dose-normalised AUC) was $34.8 \%$ coefficient of variation $(\mathrm{CV})$, which was reduced to $24.7 \% \mathrm{CV}$ when the predefined covariates for liraglutide $\mathrm{CL} / F$ were included in the population pharmacokinetic model.

Body weight and sex significantly impacted dose-normalised liraglutide exposure (Fig. 2), whereas age, race, ethnicity, glycaemic status, dose, injection site and renal function did not (additional data for exposure by renal function is included in Online Resource Fig. S3). The analysis also showed similar dose-normalised exposure for the liraglutide $3.0 \mathrm{mg}$ and $1.8 \mathrm{mg}$ groups, indicating dose proportionality in the dose range $1.8-3.0 \mathrm{mg}$, consistent with results from the phase II dose-finding trial (Fig. 1).

\subsubsection{Effect of Body weight}

Mean liraglutide exposure appeared to decrease with increasing body weight (Online Resource Fig. S1), and this was confirmed in the population pharmacokinetic analysis (Fig. 2). Compared with a reference subject weighing $100 \mathrm{~kg}$, higher body weight was associated with decreased liraglutide exposure, and lower body weight was associated with increased exposure; for a $234 \mathrm{~kg}$ subject (the highest observed body weight in the dataset), liraglutide exposure was $44 \%$ lower $(78 \%$ higher $\mathrm{CL} / F)$. Conversely, for a $60 \mathrm{~kg}$ subject (the lowest observed body weight in the dataset), liraglutide exposure was $41 \%$ higher (29\% lower $\mathrm{CL} / F)$. The $90 \% \mathrm{CI}$ values were outside of the predefined limits for bioequivalence for both the highest $(234 \mathrm{~kg})$ and lowest $(60 \mathrm{~kg})$ body weight values, indicating an effect of body weight on liraglutide exposure. Exposure by baseline BMI revealed a less clear relationship. Graphical analysis demonstrated negligible difference between subjects with

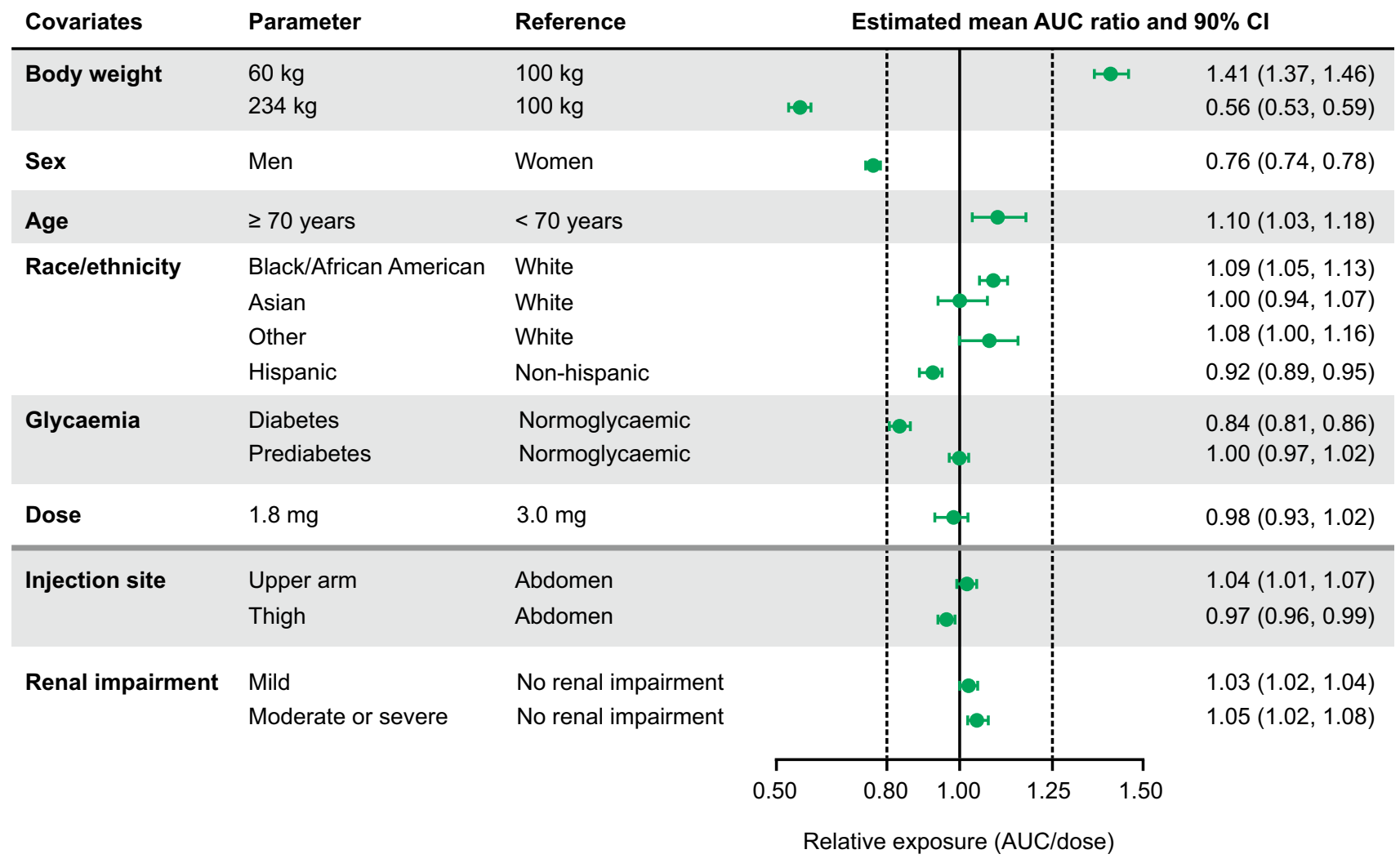

Fig. 2 Influence of covariates on exposure expressed as change in relative steady-state dose-normalised liraglutide exposure $\left(\mathrm{AUC}_{24} /-\right.$ dose). Reference subject profile: female, below 70 years of age, $100 \mathrm{~kg}$ body weight, White, non-Hispanic or -Latino, without diabetes or prediabetes, dosed by liraglutide $3.0 \mathrm{mg}$ once daily. The parameter 'body weight' shows the highest and lowest in the dataset. Mild and moderate/severe renal impairment were defined as $\geq 60$ and $<90 \mathrm{ml} \mathrm{min}{ }^{-1}$ and $\geq 30$ and $<60 \mathrm{ml} \mathrm{min}^{-1}$, respectively, and 'no renal impairment' was defined as $\geq 90 \mathrm{ml} / \mathrm{min}$. Dotted lines indicate the interval used for bioequivalence testing, for comparison. The column to the right shows geometric mean relative exposures with $90 \%$ CI obtained by likelihood profiling. Covariates above the solid horizontal line were prespecified, and parameters below the solid line were analyzed post hoc. $C I$ confidence interval, $A U C$ area under the curve 
high and low BMI when body weight was matched (data not shown). Additional statistical analyses based on post hoc estimates confirmed that, for simultaneous investigation of body weight and BMI, the influence of body weight on exposure was highly significant $(p<0.0001)$, and of similar magnitude as in the main analysis. By contrast, the BMI influence was small and of borderline significance ( $p \sim 0.03$ ). These findings suggest that absolute bodyweight, rather than obesity per se, is the better predictor of liraglutide exposure.

\subsubsection{Effect of Sex}

Liraglutide exposure was $24 \%$ lower in males than in females of comparable body weight (Fig. 2), which corresponds to $32 \%$ greater exposure in females compared with males at comparable body weight. The effect of sex on exposure was independent of the effect of body weight (Online Resource Fig. S4). Since the $90 \%$ CI for this effect was outside of the bioequivalence limits, sex was considered to have a pharmacokinetically relevant effect on liraglutide exposure.

\subsubsection{Effect of Trial: Glycaemic Status}

Subjects with T2DM were found to have $16 \%$ lower liraglutide exposure than normoglycaemic subjects, while subjects with prediabetes had similar mean exposure to normoglycaemic subjects (Fig. 2). The $90 \%$ CI for subjects with T2DM versus normoglycaemic subjects fell narrowly within the bioequivalence limits and were therefore not considered pharmacokinetically relevant. However, glycaemic status was confounded by trial as all subjects with T2DM originated from Trial 2. Therefore, a trial effect cannot be excluded. Conversely, subjects with prediabetes had similar liraglutide exposure to normoglycaemic subjects; however, in this case both groups originated from Trial 1.

The geometric mean of the individual apparent clearance estimates in the three studies was $0.94,1.22$ and $0.93 \mathrm{~L} / \mathrm{h}$ for Trials 1,2 and 3, respectively. This confirms similarity between the trials in subjects without diabetes (Trials 1 and 3), and higher clearance values for Trial 2, in subjects with diabetes. The covariate-adjusted clearance estimate was similar across the three trials (geometric mean $0.86,0.86$, and $0.88 \mathrm{~L} / \mathrm{h}$, respectively), confirming that the estimated covariate factors adequately accounted for differences between trials.

\subsubsection{Effect of Body Weight on Exposure: By Sex and Baseline Glycaemic Status}

Exposure levels at steady-state concentrations of liraglutide $3.0 \mathrm{mg}$ overlapped in male and female subjects. However, in general, males are heavier than females and therefore the combined effects of sex and body weight contribute to a generally lower exposure in males versus females. The relationship among exposure, body weight and sex is shown in Fig. 3a. Likewise, individuals with T2DM generally had lower exposure than those with normoglycaemia or prediabetes at all body weights (Fig. 3b).

\subsubsection{High and Low Exposure Scenarios Including Additional Covariates}

A 'high-exposure scenario' was generated using a female of body weight $60 \mathrm{~kg}$ (lowest observed body weight in the pharmacokinetic dataset) without T2DM using injection site 'upper arm' and additional covariates expected to give the highest exposure ( $\geq 70$ years of age, Black, non-Hispanic). A 'low-exposure scenario' was generated using a male with body weight $234 \mathrm{~kg}$ (highest observed body weight in the pharmacokinetic dataset) with T2DM using injection site 'thigh', and additional covariates expected to give the lowest exposure ( $<70$ years of age, White, Hispanic). Predicted liraglutide exposure values (AUC) for the high- and low-exposure scenarios were 1631 and $297 \mathrm{nM} \mathrm{h}$, respectively. These predicted exposure levels were covered by the actual observed exposure levels.

\subsubsection{Exposure Comparison: Liraglutide $3.0 \mathrm{mg}$ in Overweight/Obese Subjects Versus $1.8 \mathrm{mg}$ in Subjects with Type 2 Diabetes Mellitus}

Liraglutide $1.8 \mathrm{mg}$ is approved for use in subjects with T2DM, and safety data are available both from the clinical trial programme and postmarketing experience. To evaluate the applicability of safety data for liraglutide $1.8 \mathrm{mg}$ in subjects with T2DM with liraglutide $3.0 \mathrm{mg}$ in overweight/ obese subjects, an exposure comparison was undertaken.

The predicted estimated exposure distribution associated with liraglutide $3.0 \mathrm{mg}$ in overweight/obese subjects in Trials 1 and 2 was compared with the estimated exposure of liraglutide $1.8 \mathrm{mg}$ in subjects with T2DM in a previous phase III trial [26]. As shown in Fig. 4, there is substantial overlap in exposures with liraglutide 3.0 and $1.8 \mathrm{mg}$ when used for weight management and treatment of T2DM, respectively, in overweight/obese subjects with and without T2DM; approximately $16 \%$ of the overweight/obese population receiving $3.0 \mathrm{mg}$ reach exposures higher than any exposure in subjects with T2DM treated with $1.8 \mathrm{mg}$. Approximately one-third of the difference in exposure between Trials 1 and 2 (29\% higher exposure in Trial 1) could be explained by the higher proportion of females in Trial 1 (78 vs. $48 \%$ ). The remaining $19 \%$ may be attributed to differences in exposure in subjects with and without T2DM. 


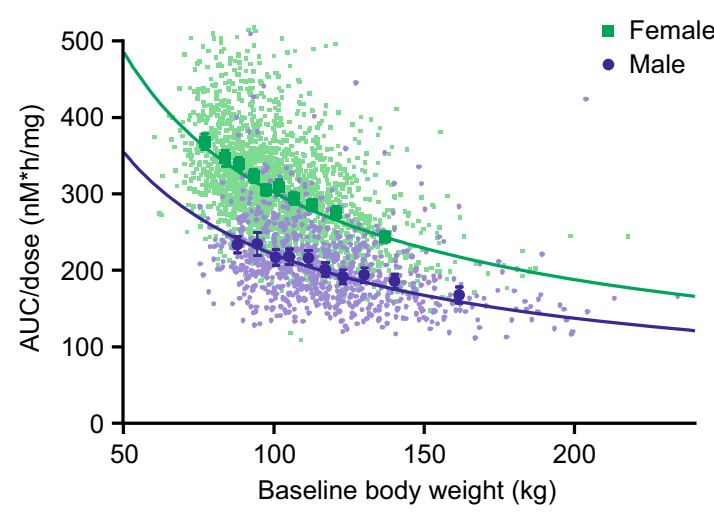

Fig. 3 Liraglutide exposure versus body weight stratified by a sex and b glycaemic status. Data are dose-normalised mean AUC values with $95 \%$ CI for quantiles of baseline body weight (large symbols)

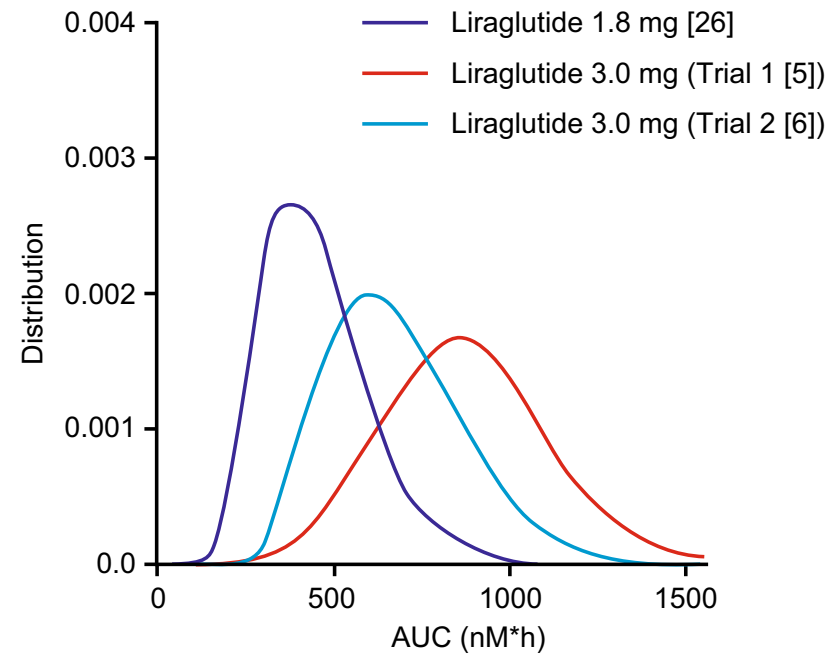

Fig. 4 Exposure distribution (patient frequency) predicted for liraglutide $3.0 \mathrm{mg}$ in overweight/obese subjects with (Trial 2 [6]) and without T2DM (Trial 1 [5]) compared with liraglutide $1.8 \mathrm{mg}$ in subjects with T2DM [26]. AUC area under the curve, T2DM type 2 diabetes mellitus

\section{Discussion}

This analysis demonstrated that exposure of liraglutide, within the dose range $1.2-3.0 \mathrm{mg}$, is dose proportional in obese adults. Furthermore, the population pharmacokinetic assessment established a plasma clearance value for liraglutide $3.0 \mathrm{mg}$ in overweight and obese adults of between 0.9 and $1.4 \mathrm{~L} / \mathrm{h}$, and demonstrated that exposure of liraglutide $3.0 \mathrm{mg}$ in an overweight or obese population is mainly impacted by two key covariates-body weight and sex.

These findings are consistent with the established pharmacokinetic properties of liraglutide at lower doses [36]. Dose-proportional exposure has been demonstrated in the $0.6-1.8 \mathrm{mg}$ dose range in healthy adults $[37,38]$ and those with T2DM [39, 40]. Furthermore, body weight and

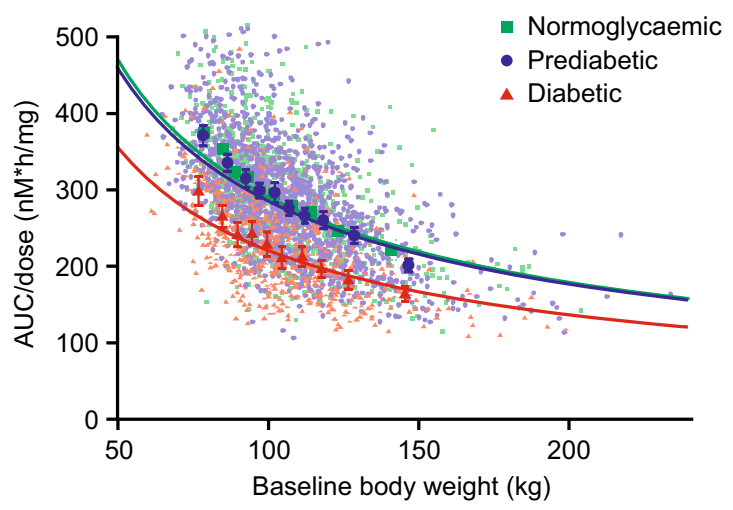

and individual exposure estimates (small symbols). Lines are modelbased relationships adjusted for other covariate effects. $A U C$ area under the curve, $C I$ confidence interval

sex (but not age, race or ethnicity) were previously found to be relevant covariates for liraglutide $(1.2-1.8 \mathrm{mg})$ clearance, and hence exposure, in a population pharmacokinetic analysis in subjects with T2DM and mean body weight of $90 \mathrm{~kg}$ [26].

Reasons for the lower weight-adjusted clearance of liraglutide in females than males, and the effects of differences in body composition and other factors, have yet to be determined. Further analysis of the exposure-response relationship demonstrated increasing weight loss response at increasing exposure levels throughout the exposure range, with clear effects apparent in the low exposure range. With the exception of gastrointestinal tolerability, safety and tolerability were not exposure-dependent [41]. Therefore, exposure-response analysis supported use of the highest tested dose of liraglutide $(3.0 \mathrm{mg})$ in all subpopulations, and did not support differential dosing in males versus females or in heavier versus lighter individuals [41].

Liraglutide is endogenously metabolised without a specific organ as a major route of elimination [42]. In accordance with this, post hoc analysis demonstrated that clearance of liraglutide $3.0 \mathrm{mg}$ is not impacted by mild $\left(\mathrm{CrCl} \geq 60\right.$ and $\left.<90 \mathrm{ml} \mathrm{min}^{-1}\right)$ or moderate $(\mathrm{CrCl} \geq 30$ and $<60 \mathrm{ml} \mathrm{min}^{-1}$ ) renal impairment, although we recognise that use of epidermal growth factor receptor (eGFR) may have led to overestimation of true GFR in this obese population [43]. While this suggests that dose adjustment of liraglutide $3.0 \mathrm{mg}$ is not required in renal impairment (as is also the case for liraglutide $1.8 \mathrm{mg}$ ) [44, 45], experience with liraglutide $3.0 \mathrm{mg}$ in patients with severe renal impairment $\left(\mathrm{CrCl}<30 \mathrm{ml} \mathrm{min}^{-1}\right)$, including end-stage renal disease, is limited. Use in this group is therefore not recommended [1], and caution is advised when initiating or escalating doses of liraglutide in these patients [1]. The post hoc analysis also found no difference in CL/ $F$ values for liraglutide across injection sites (abdomen, thigh or upper arm), suggesting that injection site can be guided by 
patient preference. Since the effects of adding renal function and/or injection site to the model are minimal, and the shrinkage in clearance is small, these effects would remain eligible if the prespecified model was revised to include these parameters.

Covariate analysis showed that subjects with low body weight will achieve higher liraglutide exposure than subjects with high body weight. Therefore, the liraglutide exposure level was compared between the weight management programme (with the higher dose $3.0 \mathrm{mg}$ and heavier subjects [body weight range $60-234 \mathrm{~kg}$ ]) and liraglutide $1.8 \mathrm{mg}$ in subjects with T2DM (phase III trial with body weight range 40-160 kg [26]). The substantial overlap in exposures in the two programmes indicates that safety data obtained with liraglutide $1.8 \mathrm{mg}$ can usefully inform dosing with liraglutide $3.0 \mathrm{mg}$. To further evaluate the safe use of liraglutide in subjects with overweight/ obesity, in particular for exposure levels exceeding the range obtained with $1.8 \mathrm{mg}$, an exposure-response evaluation was conducted for selected safety parameters and has been published separately [41].

\section{Conclusions}

Exposure of liraglutide up to and including $3.0 \mathrm{mg}$ in overweight and obese adults is dose proportional. For liraglutide $3.0 \mathrm{mg}$, sex and body weight are the main baseline covariates influencing exposure, while age $\geq 70$ years, race, ethnicity, glycaemic status, mild-tomoderate renal impairment, injection site and dose are not considered pharmacokinetically relevant. Further exposure-response analyses in relevant subgroups are required to support dosing recommendations of liraglutide $3.0 \mathrm{mg}$ for weight management.

Acknowledgments Medical writing assistance was provided by Rosalyn Ferguson and Esther Nathanson at Watermeadow Medical, UK, supported by Novo Nordisk A/S.

Author Contributions Rune V. Overgaard participated in planning and conducting the analyses, data interpretation, and drafting of this article. Kristin C. Petri participated in planning and conducting the analyses, data interpretation, and drafting of this article. Lisbeth V. Jacobsen participated in planning of the analyses, data interpretation and drafting of this article. Christine B. Jensen participated in trial design, trial conduct, planning of the analyses, data interpretation, and drafting of this article. All authors had full access to all the data used in the analyses and take responsibility for the integrity of the data and the accuracy of the data analysis. All authors approved the final version.

\section{Compliance with Ethical Standards}

Conflict of interest Rune V. Overgaard, Kristin C. Petri, Lisbeth V. Jacobsen and Christine B. Jensen are all employees of, and shareholders in, Novo Nordisk A/S. No other relationships or activities appear to have influenced the submitted work.

Open Access This article is distributed under the terms of the Creative Commons Attribution-NonCommercial 4.0 International License (http://creativecommons.org/licenses/by-nc/4.0/), which permits any noncommercial use, distribution, and reproduction in any medium, provided you give appropriate credit to the original author(s) and the source, provide a link to the Creative Commons license, and indicate if changes were made.

\section{References}

1. Saxenda ${ }^{\circledR}$ (liraglutide) highlights of prescribing information. Novo Nordisk Inc. 2015. Available at: http://www.novo-pi.com/ saxenda.pdf. Accessed Oct 2015.

2. Saxenda ${ }^{\circledR}$ (liraglutide) summary product information. Novo Nordisk Canada Inc. 2015. Available at: http://www.novonordisk. $\mathrm{ca} /$ content/dam/Canada/AFFILIATE/www-novonordisk-ca/Our Products/PDF/Saxenda_PM_English.pdf. Accessed Aug 2015.

3. Saxenda ${ }^{\circledR}$ (liraglutide) summary product information. European Medicines Agency. 2015. Available at: http://ec.europa.eu/health/ documents/community-register/2015/20150323131125/anx_131125_ en.pdf. Accessed Sep 2015.

4. Federación Mexicana de Diabetes A.C. COFEPRIS approved the first treatment for chronic management of obesity in Mexico [press release], Feb 2015. Available at: http://fmdiabetes.org/ aprueba-la-cofepris-primer-tratamiento-para-el-manejo-cronico-dela-obesidad-en-mexico/. Accessed Nov 2015.

5. Pi-Sunyer X, Astrup A, Fujioka K, Greenway F, Halpern A, Krempf M, SCALE Obesity and Prediabetes NN8022-1839 Study Group, et al. A randomized, controlled trial of $3.0 \mathrm{mg}$ of liraglutide in weight management. N Engl J Med. 2015;373:11-22.

6. Davies M, Bode B, Kushner R, Kushner RF, Lewin A, Skjøth TV, NN8022-1922 Study Group, et al. Efficacy of liraglutide for weight loss among patients with type 2 diabetes: the SCALE diabetes randomized clinical trial. JAMA. 2015;314:687-99.

7. Secher A, Jelsing J, Baquero AF, Hecksher-Sørensen J, Cowley MA, Dalbøge LS, et al. The arcuate nucleus mediates GLP-1 receptor agonist liraglutide-dependent weight loss. J Clin Invest. 2014; 124:4473-88.

8. van Can CJ, Sloth B, Jensen CB, Flint A, Blaak EE, Saris WH. Effects of the once-daily GLP-1 analog liraglutide on gastric emptying, glycemic parameters, appetite and energy metabolism in obese, non-diabetic adults. Int J Obes (Lond). 2014;38:784-93.

9. Jensen MD, Ryan DH, Apovian CM, Ard JD, Comuzzie AG, Donato KA, American College of Cardiology/American Heart Association Task Force on Practice Guidelines, Obesity Society, et al. 2013 AHA/ACC/TOS guideline for the management of overweight and obesity in adults: a report of the American College of Cardiology/American Heart Association Task Force on Practice Guidelines and The Obesity Society. J Am Coll Cardiol. 2014;63:2985-3023.

10. Eckel RH, Kahn SE, Ferrannini E, Goldfine AB, Nathan DM, Schwartz MW, et al. Obesity and type 2 diabetes: what can be unified and what needs to be individualized? J Clin Endocrinol Metab. 2011;96:1654-63.

11. Selvin E, Parrinello CM, Sacks DB, Coresh J. Trends in prevalence and control of diabetes in the United States, 1988-1994 and 1999-2010. Ann Intern Med. 2014;160:517-25.

12. Guh DP, Zhang W, Bansback N, Amarsi Z, Birmingham CL, Anis $\mathrm{AH}$. The incidence of co-morbidities related to obesity and 
overweight: a systematic review and meta-analysis. BMC Public Health. 2009;9:88.

13. Khaodhiar L, McCowen KC, Blackburn GL. Obesity and its comorbid conditions. Clin Cornerstone. 1999;2:17-31.

14. Collaboration Prospective Studies, Whitlock G, Lewington S, Sherliker P, Clarke R, Emberson J, et al. Body-mass index and cause-specific mortality in 900,000 adults: collaborative analyses of 57 prospective studies. Lancet. 2009;373:1083-96.

15. Blagojevic M, Jinks C, Jeffery A, Jordan KP. Risk factors for onset of osteoarthritis of the knee in older adults: a systematic review and meta-analysis. Osteoarthritis Cartilage. 2010;18:24-33.

16. Dahaghin S, Bierma-Zeinstra SM, Koes BW, Hazes JM, Pols HA. Do metabolic factors add to the effect of overweight on hand osteoarthritis? The Rotterdam Study. Ann Rheum Dis. 2007;66:916-20.

17. Phelan S, Kanaya AM, Subak LL, Hogan PE, Espeland MA, Wing RR, Action for Health in Diabetes (Look AHEAD) Research Group, et al. Prevalence and risk factors for urinary incontinence in overweight and obese diabetic women: action for health in diabetes (look ahead) study. Diabetes Care. 2009;32: 1391-7.

18. Subak LL, Whitcomb E, Shen H, Saxton J, Vittinghoff E, Brown JS. Weight loss: a novel and effective treatment for urinary incontinence. J Urol. 2005;174:190-5.

19. Bray GA. Health hazards of obesity. Endocrinol Metab Clin North Am. 1996;25:907-19.

20. Wadden TA, Stunkard AJ. Social and psychological consequences of obesity. Ann Intern Med. 1985;103:1062-7.

21. Jia H, Lubetkin EI. The impact of obesity on health-related quality-of-life in the general adult US population. J Public Health (Oxf). 2005;27:156-64.

22. Rueda-Clausen CF, Padwal RS, Sharma AM. New pharmacological approaches for obesity management. Nat Rev Endocrinol. 2013;9:467-78.

23. Apovian CM, Aronne LJ, Bessesen DH, McDonnell ME, Murad $\mathrm{MH}$, Pagotto U, et al. Endocrine Society. Pharmacological management of obesity: an endocrine Society clinical practice guideline. J Clin Endocrinol Metab. 2015;100:342-62.

24. US FDA. Guidance for industry. Developing products for weight management. Draft Guidance. 2007. Available at: http://www. fda.gov/downloads/Drugs/Guidances/ucm071612.pdf. Accessed June 2015.

25. Hurt RT, Edakkanambeth VJ, Ebbert JO. New pharmacological treatments for the management of obesity. Curr Gastroenterol Rep. 2014;16:394.

26. Ingwersen SH, Khurana M, Madabushi R, Watson E, Jonker DM, Le Thi TD, et al. Dosing rationale for liraglutide in type 2 diabetes mellitus: a pharmacometric assessment. J Clin Pharmacol. 2012;52:1815-23.

27. Astrup A, Rossner S, Van GL, Rissanen A, Niskanen L, Al Hakim M, et al. NN8022-1807 Study Group. Effects of liraglutide in the treatment of obesity: a randomised, double-blind, placebocontrolled study. Lancet. 2009;374:1606-16.

28. Hu C, Zhang J, Zhou H. Confirmatory analysis for phase III population pharmacokinetics. Pharm Stat. 2011;10:14-26.

29. US FDA. Guidance for industry. Population pharmacokinetics. 2009. Available at: http://www.fda.gov/downloads/Drugs/Guidances/ UCM072137.pdf. Accessed June 2015.

30. EMA. Guideline on the investigation of drug interactions. 2012. Available at: http://www.ema.europa.eu/docs/en_GB/document library/Scientific_guideline/2012/07/WC500129606.pdf. Accessed June 2015.
31. Levey AS, Stevens LA, Schmid CH, Zhang YL, Castro AF 3rd, Feldman HI, CKD-EPI (Chronic Kidney Disease Epidemiology Collaboration, et al. A new equation to estimate glomerular filtration rate. CKD-EPI (Chronic Kidney Disease Epidemiology Collaboration). Ann Intern Med. 2009;150:604-12.

32. Agers $\emptyset$ H, Jensen LB, Elbrond B, Rolan P, Zdravkovic M. The pharmacokinetics, pharmacodynamics, safety and tolerability of NN2211, a new long-acting GLP-1 derivative, in healthy men. Diabetologia. 2002;45:195-202.

33. Agers $\varnothing \mathrm{H}$, Vicini P. Pharmacodynamics of NN2211, a novel long acting GLP-1 derivative. Eur J Pharm Sci. 2003;19:141-50.

34. World Medical Association. Declaration of Helsinki: ethical principles for medical research involving human subjects. 2013. Available at: http://www.wma.net/en/30publications/10policies/ b3/. Accessed June 2015.

35. International Conference on Harmonisation. ICH Harmonised Tripartite Guideline. Good Clinical Practice. 1996. Available at: http://www.ich.org/fileadmin/Public_Web_Site/ICH_Products/ Guidelines/Efficacy/E6/E6_R1_Guideline.pdf. Accessed June 2015.

36. Jacobsen LV, Flint A, Olsen AK, Ingwersen SH. Liraglutide in type 2 diabetes mellitus: clinical pharmacokinetics and pharmacodynamics. Clin Pharmacokinet. doi:10.1007/s40262-015-03436. Epub 23 Nov 2015.

37. Elbrønd B, Jakobsen G, Larsen S, Agers $\varnothing$ H, Jensen LB, Rolan P, et al. Pharmacokinetics, pharmacodynamics, safety, and tolerability of a single-dose of NN2211, a long-acting glucagon-like peptide 1 derivative, in healthy male subjects. Diabetes Care. 2002;25:1398-404.

38. Jiang J, Zhang J, Jacobsen LV, Hu P. The pharmacokinetics, pharmacodynamics, and tolerability of liraglutide, a once-daily human GLP-1 analogue, after multiple subcutaneous administration in healthy Chinese male subjects. J Clin Pharmacol. 2011;51:1620-7.

39. Ingwersen SH, Petri KC, Tandon N, Yoon KH, Chen L, Vora J, et al. Liraglutide pharmacokinetics and dose-exposure response in Asian subjects with Type 2 diabetes from China, India and South Korea. Diabetes Res Clin Pract. 2015;108:113-9.

40. Watson E, Jonker DM, Jacobsen LV, Ingwersen SH. Population pharmacokinetics of liraglutide, a once-daily human glucagonlike peptide-1 analog, in healthy volunteers and subjects with type 2 diabetes, and comparison to twice-daily exenatide. J Clin Pharmacol. 2010;50:886-94.

41. Wilding JP, Overgaard RV, Jacobsen LV, Jensen CB, le Roux $\mathrm{CW}$. Exposure-response analyses of liraglutide $3.0 \mathrm{mg}$ for weight management. Diabetes Obes Metab. 2016;18(5):491-9.

42. Malm-Erjefält M, Bjørnsdottir I, Vanggaard J, Helleberg H, Larsen U, Oosterhuis B, et al. Metabolism and excretion of the once-daily human glucagon-like peptide-1 analog liraglutide in healthy male subjects and its in vitro degradation by dipeptidyl peptidase IV and neutralendopeptidase. Drug Metab Dispos. 2010;38:1944-53.

43. Pai MP. Estimating the glomerular filtration rate in obese adult patients for drug dosing. Adv Chronic Kidney Dis. 2010;17:e53-62.

44. Victoza ${ }^{\circledR}$ (liraglutide) Summary of product characteristics. 2014. Available at: http://www.ema.europa.eu/docs/en_GB/document_ library/EPAR___Product_Information/human/001026/WC500050017. pdf. Accessed Aug 2015.

45. Victoza ${ }^{\circledR}$ (liraglutide) Highlights of prescribing information. 2010. Available at: https://www.accessdata.fda.gov/drugsatfda docs/label/2010/022341lbl.pdf. Accessed Sep 2015. 